\title{
Clear Discrepancy in Neurofibromin Expression between NF1 Pheochromocytoma Cells and Non-Tumorous Adrenal Medullary Cells
}

\author{
Koji Mikami'1, Yumiko Okuno', Masayoshi Zaitsu', Hiroki Tanaka², Koichi Sakazume², \\ Akiko Tonooka², Toshimasa Uekusa ${ }^{2}$, Takumi Takeuchi ${ }^{*}$ \\ ${ }^{1}$ Department of Urology, Kanto Rosai Hospital, Kawasaki, Japan \\ ${ }^{2}$ Department of Pathology, Kanto Rosai Hospital, Kawasaki, Japan \\ Email: "takeuchit@abelia.ocn.ne.jp
}

Received 15 March 2016; accepted 17 May 2016; published 20 May 2016

Copyright (C) 2016 by authors and Scientific Research Publishing Inc.

This work is licensed under the Creative Commons Attribution International License (CC BY).

http://creativecommons.org/licenses/by/4.0/

c) (i) Open Access

\begin{abstract}
Neurofibromatosis type 1 (NF1) is a common inherited disorder with an autosomal dominant trait. We encountered an NF1 patient who showed adrenal pheochromocytoma, and analyzed expression of neurofibromin in an excised specimen. A 54-year-old man showing multiple neurofibromas and café-au-lait spots in the skin was pointed out to have a right adrenal tumor by ultrasonography. Abdominal CT also revealed a right adrenal tumor. He was diagnosed with neurofibromatosis type 1 with no family history. Urine catecholamines, metanephrine, and normetanephrine levels were elevated. MIBG scintigraphy showed positive right adrenal uptake, and so pheochromocytoma was also diagnosed. The patient underwent laparoscopic right adrenalectomy. The excised adrenal specimen of this patient was stained with anti-neurofibromin polyclonal antibody. The NF1 pheochromocytoma was completely negative for neurofibromin protein expression, while the NF1 non-pheochromocytomatous adrenal medulla was neurofibromin-positive in the cytoplasm and nucleus. The clear discrepancy in neurofibromin expression between pheochromocytoma cells and "normal" adrenal medullary cells of the patient may well be explained by Knudson's twohit hypothesis.
\end{abstract}

\section{Keywords}

Pheochromocytoma, NF1, Neurofibromin

\footnotetext{
"Corresponding author.
}

How to cite this paper: Mikami, K., Okuno, Y., Zaitsu, M., Tanaka, H., Sakazume, K., Tonooka, A., Uekusa, T. and Takeuchi, T. (2016) Clear Discrepancy in Neurofibromin Expression between NF1 Pheochromocytoma Cells and Non-Tumorous Adrenal Medullary Cells. Open Journal of Urology, 6, 86-90. http://dx.doi.org/10.4236/oju.2016.65016 


\section{Introduction}

Neurofibromatosis type 1 (NF1) is a common inherited disorder with an autosomal dominant trait caused by mutations of the NF1 gene of $360 \mathrm{~kb}$ and 73 exons located at chromosome 17q11.2. The incidence rate of NF1 is about 1 in 3500 [1]. The diagnosis of NF1 is based on clinical assessment and requires two or more of the following features: (a) 6 or more café-au-lait macules, (b) 2 or more cutaneous/subcutaneous neurofibromas or one plexiform neurofibroma, (c) axillary or groin freckling, (d) optic pathway glioma, (e) 2 or more Lisch nodules (iris hamartomas), (f) bony dysplasia, (g) first degree relative with NF1 [2]. NF1 also shows learning deficits and predisposition to the formation of various types of benign/malignant tumors including pheochromocytoma [3]-[5].

Neurofibromin, the product of the NF1 gene of 2818 amino acids, is a Ras-GTPase-activating protein, negatively regulates the Ras/MAPK, PI3K, and mTOR signaling pathways [6] [7], and functions as a tumor suppressor protein. Here, we encountered an NF1 patient who showed pheochromocytoma and analyzed the expression of neurofibromin in an excised adrenal specimen.

\section{Case Report}

A 54-year-old man was pointed out to have a right adrenal tumor on ultrasonography during ordinary health screening and was referred to the Department of Endocrinology of Kanto Rosai Hospital. His height was $170 \mathrm{~cm}$ and his weight was $63 \mathrm{~kg}$. His systolic/diastolic blood pressures on admission were 146/86 mmHg with the administration of anti-hypertensive drugs, heart rate 78 beats per minute, saturation $98 \%$ on room air. The electrocardiogram showed left ventricular hypertrophy. The man showed multiple neurofibromas and café-au-lait spots in the skin (Figure 1) and Lisch nodules were ophthalmologically found. So, he was also diagnosed with neurofibromatosis type 1 with no family history. He had no skeletal abnormalities or learning deficits.

Abdominal CT also revealed a right adrenal tumor of $3.0 \mathrm{~cm}$ in diameter (Figure 2). Urine catecholamines, metanephrine, and normetanephrine levels were elevated, as shown in Table 1. MIBG scintigraphy showed positive right adrenal uptake (Figure 3), and so pheochromocytoma was diagnosed.

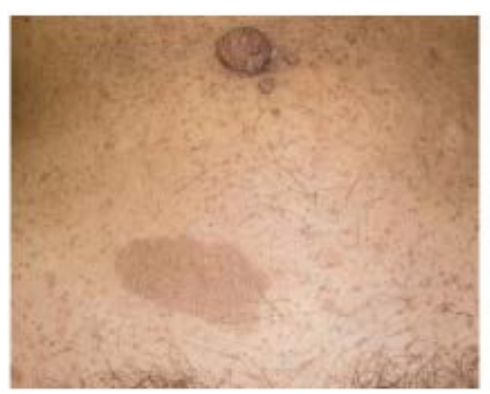

café-au-lait spot

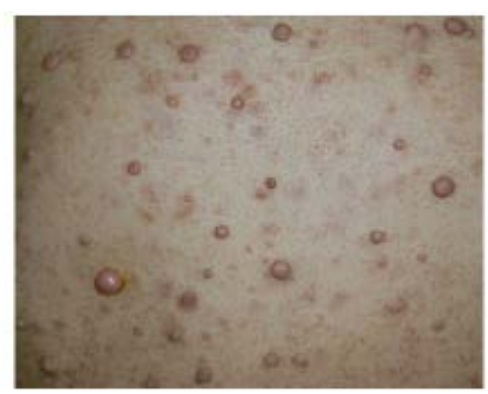

Neurofibromas

Figure 1. Skin lesions, neurofibromas and a café-au-lait spot.

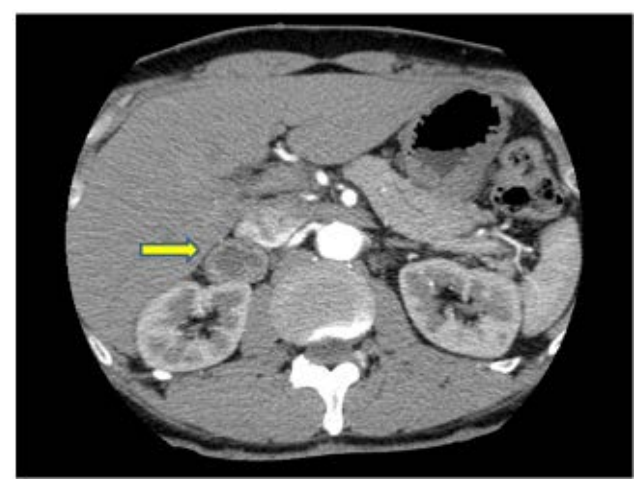

Figure 2. An abdominal CT scan. The yellow arrow indicates a right adrenal tumor. 
Table 1. Urine catecholamines, metanephrine, and normetanephrine levels before right adrenalectomy.

\begin{tabular}{ccc}
\hline Adrenalin & $58.9 \mu \mathrm{g} / \mathrm{day}$ & $(3.4-26.9)$ \\
Noradrenalin & $457.9 \mu \mathrm{g} / \mathrm{day}$ & $(48.6-168.5)$ \\
Dopamine & $2786.2 \mu \mathrm{g} / \mathrm{day}$ & $(365.0-961.5)$ \\
Metanephrine & $0.55 \mathrm{mg} / \mathrm{day}$ & $(0.04-0.19)$ \\
Normetanephrine & $0.94 \mathrm{mg} /$ day & $(0.09-0.33)$ \\
\hline
\end{tabular}

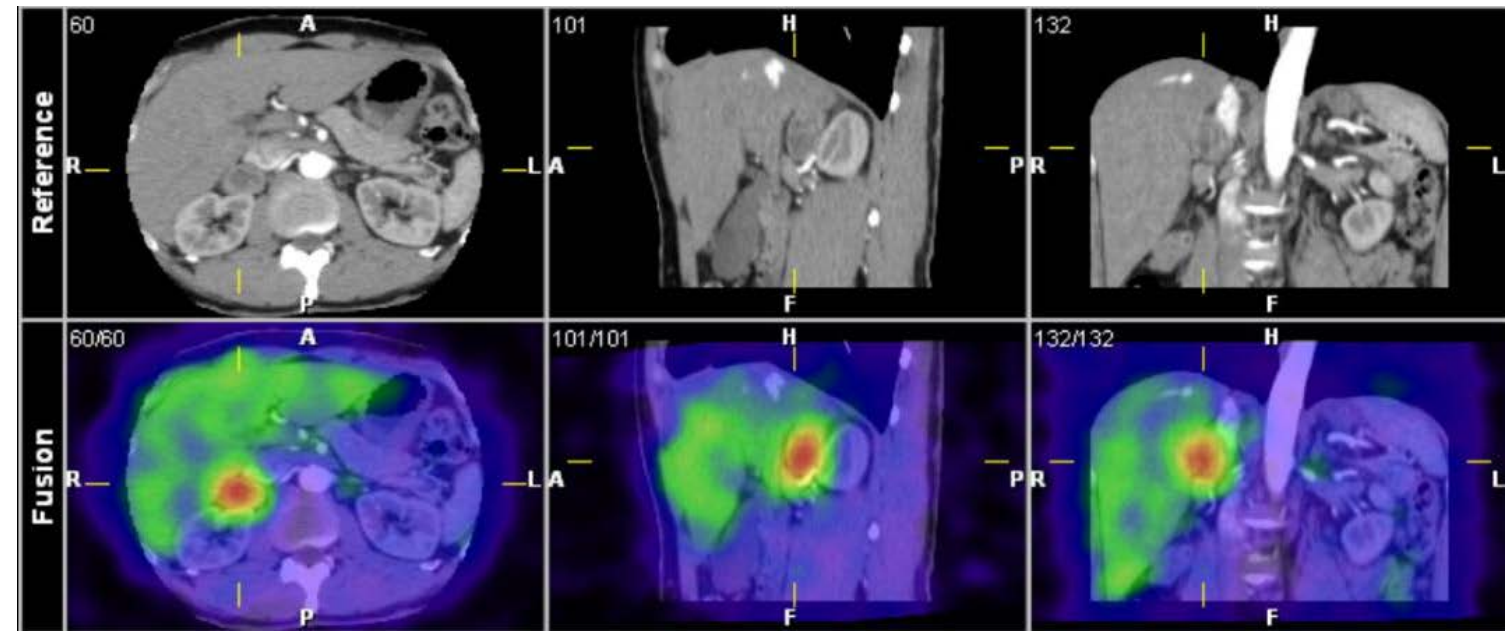

Figure 3. MIBG scintigraphy indicating positive right adrenal uptake.

The patient underwent laparoscopic right adrenalectomy under general anesthesia. During mobilization of the tumor, the systolic blood pressure elevated to as high as $200 \mathrm{mmHg}$, then it dropped to around $80 \mathrm{mmHg}$ following ligation of the right adrenal veins. The post-operative course was uneventful. The pathology was pheochromocytoma with positive staining of chromogranin A (Figure 4) and histological characteristics implying malignant potential were not observed. One year after right adrenalectomy, there was no recurrence of pheochromocytoma and his systolic/diastolic blood pressures were 120/74 mmHg.

\section{Immunohistochemistry of Neurofibromin}

An excised adrenal specimen of this patient as well as a sporadic pheochromocytoma was stained with antineurofibromin polyclonal antibody (ab30325, Abcam, Cambridge, UK). As shown in Figure 4, the NF1 pheochromocytoma was completely negative for neurofibromin protein expression, while the non-pheochromocytomatous adrenal medulla was neurofibromin-positive in the cytoplasm and nucleus. Sporadic pheochromocytoma of a non-NF1 patient was positively stained for neurofibromin in the cytoplasm and nucleus.

\section{Discussion}

Sporadic NF1 cases without a family history comprise 30\% - 50\% among all NF1 patients, and the significance of advanced paternal age has been indicated [8] [9]. Those cases are caused by a novel mutation in the NF1 gene in the germ cell of either parent. According to Knudson's two-hit hypothesis of hereditary tumors, a germline mutation in a tumor suppressor gene in one allele is inherited and another mutation in the other allele is generated in somatic cells by the second hit. The second hit is not rare, and so the cancer susceptibility is actually inherited dominantly [10]. Following this two-hit theory, pheochromocytoma cells in this case must have NF1 mutations in both alleles, while "normal" adrenal medullar cells of the patient theoretically have NF1 mutation in one allele only. A clear discrepancy in neurofibromin staining between pheochromocytoma cells and "normal” adrenal medullary cells may well be explained by the two-hit hypothesis in the present case. 

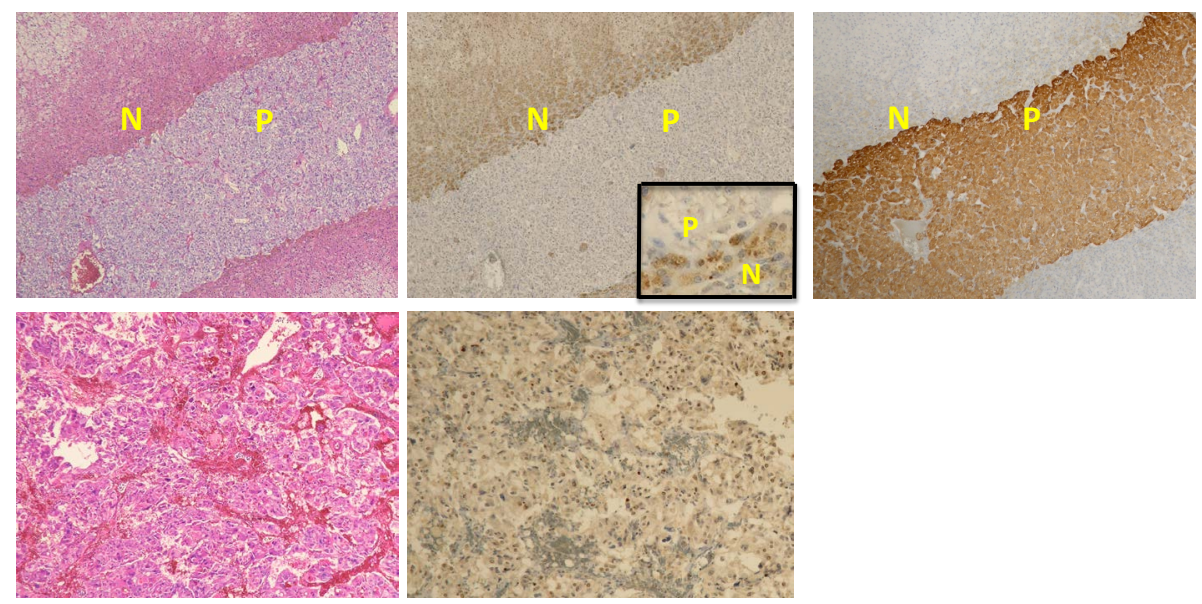

Figure 4. Hematoxylin \& Eosin staining (left) and immunohistochemistry of neurofibromin (middle)/ chromogranin A (right). Upper: an NF1 pheochromocytoma, Lower: a sporadic non-NF1 pheochromocytoma. N: non-pheochromatous adrenal medulla, P: pheochromocytoma. The border of the nonpheochromatous NF1 adrenal medulla and NF1 pheochromocytoma is magnified at the corner.

Pheochromocytomas were clinically identified in 5.7\% of NF1 patients, while $9.6 \%$ of those tumors was bilateral, $6.1 \%$ was extra-adrenal, and $11.5 \%$ was malignant [11]. The present case was a solitary, unilateral, adrenal, and benign pheochromocytoma with a common clinical manifestation. However, there are not preceding reports that clearly differentiate histological neurofibromin expression between an NF1 pheochromocytoma and its surrounding non-tumorous adrenal medulla, strongly supporting Knudson's two-hit hypothesis.

Gutmann et al. reported that seven NF1 pheochromocytoma tissues did not express neurofibromin protein at all based on Western blotting [12], while Kimura et al. showed that an NF1 pheochromocytoma expressed NF1 mRNA and neurofibromin protein assessed by restriction enzyme digestion of PCR products and immunohistochemistry, respectively [13]. The latter NF1 case may have mutations in NF1 genes of both alleles, either of which is transcribed and translated into aberrant neurofibromin protein without its full function. $\mathrm{Nf}+/-$ mice heterozygous for human NF1 homologue mutation are highly susceptible to the formation of various types of tumor, notably pheochromocytomas. Nf1-/- mice were mid-embryonic lethal due to abnormal cardiac development [14].

Hereditary pheochromocytomas are also observed in von Hippel-Lindau disease (VHL gene), multiple endocrine neoplasia type 2 (RET gene), and pheochromocytoma/paraganglioma syndrome (SDHx genes) in addition to NF1 [4] [5]. Moreover, 23.8\% of sporadic pheochromocytomas exhibited somatic NF1 mutations [15]. The sporadic non-NF1 pheochromocytoma shown in Figure 4 may not have NF1 mutations in either allele, as neurofibromin protein was expressed in pheochromocytoma cells.

\section{Conclusion}

In conclusion, here we presented a case of NF1 pheochromocytoma in which neurofibromin protein expression was clearly distinct between pheochromocytoma cells and non-pheochromocytomatous adrenal medullary cells, supporting Knudson's two-hit hypothesis.

\section{Acknowledgements}

We thank Junzo Tomoishi, who passed away in 2015, for his scientific contribution to this article.

\section{Disclosure}

The authors declare that there is no conflict of interest regarding the publication of this paper.

\section{References}

[1] Theos, A. and Korf, B.R. (2006) Pathophysiology of Neurofibromatosis Type 1. Annals of Internal Medicine, 144, 
842-849. http://dx.doi.org/10.7326/0003-4819-144-11-200606060-00010

[2] (1988) National Institutes of Health Consensus Development Conference Statement: Neurofibromatosis. Archives of Neurology, 45, 575-578.

[3] Laycock-van Spyk, S., Thomas, N., Cooper, D.N. and Upadhyaya, M. (2011) Neurofibromatosis Type 1-Associated Tumours: Their Somatic Mutational Spectrum and Pathogenesis. Human Genomics, 5, 623-690. http://dx.doi.org/10.1186/1479-7364-5-6-623

[4] Kolačkov, K., Tupikowski, K. and Bednarek-Tupikowska, G. (2012) Genetic Aspects of Pheochromocytoma. Advances in Clinical and Experimental Medicine, 21, 821-829.

[5] Welander, J., Söderkvist, P. and Gimm, O. (2013) The NF1 Gene: A Frequent Mutational Target in Sporadic Pheochromocytomas and Beyond. Endocrine-Related Cancer, 20, C13-C17. http://dx.doi.org/10.1530/ERC-13-0046

[6] Harrisingh, M.C. and Lloyd, A.C. (2004) Ras/Raf/ERK Signalling and NF1. Cell Cycle, 3, 1255-1258. http://dx.doi.org/10.4161/cc.3.10.1182

[7] Le, L.Q. and Parada, L.F. (2007) Tumor Microenvironment and Neurofibromatosis Type I: Connecting the GAPs. Oncogene, 26, 4609-4616. http://dx.doi.org/10.1038/sj.onc.1210261

[8] Snajderova, M., Riccardi, V.M., Petrak, B., Zemkova, D., Zapletalova, J., Mardesic, T., Petrakova, A., Lanska, V., Marikova, T., Bendova, S., Havlovicova, M. and Kaluzova, M. (2012) The Importance of Advanced Parental Age in the Origin of Neurofibromatosis Type 1. American Journal of Medical Genetics Part A, 158A, 519-523. http://dx.doi.org/10.1002/ajmg.a.34413

[9] Bunin, G.R., Needle, M. and Riccardi, V.M. (1997) Paternal Age and Sporadic Neurofibromatosis 1: A Case-Control Study and Consideration of the Methodological Issues. Genetic Epidemiology, 14, 507-516. http://dx.doi.org/10.1002/(SICI)1098-2272(1997)14:5<507::AID-GEPI5>3.0.CO;2-Y

[10] Berger, A.H., Knudson, A.G. and Pandolfi, P.P. (2011) A Continuum Model for Tumour Suppression. Nature, 476, 163-169. http://dx.doi.org/10.1038/nature10275

[11] Walther, M.M., Herring, J., Enquist, E., Keiser, H.R. and Linehan, W.M. (1999) von Recklinghausen's Disease and Pheochromocytomas. The Journal of Urology, 162, 1582-1586. http://dx.doi.org/10.1016/S0022-5347(05)68171-2

[12] Gutmann, D.H., Cole, J.L., Stone, W.J., Ponder, B.A. and Collins, F.S. (1994) Loss of Neurofibromin in Adrenal Gland Tumors from Patients with Neurofibromatosis Type 1. Genes, Chromosomes and Cancer, 10, 55-58. http://dx.doi.org/10.1002/gcc.2870100109

[13] Kimura, N., Watanabe, T., Fukase, M., Wakita, A., Noshiro, T. and Kimura, I. (2002) Neurofibromin and NF1 Gene Analysis in Composite Pheochromocytoma and Tumors Associated with von Recklinghausen's Disease. Modern Pathology, 15, 183-188. http://dx.doi.org/10.1038/modpathol.3880513

[14] Jacks, T., Shih, T.S., Schmitt, E.M., Bronson, R.T., Bernards, A. and Weinberg, R.A. (1994) Tumor Predisposition in Mice Heterozygous for a Targeted Mutation in NF1. Nature Genetics, 7, 353-361. http://dx.doi.org/10.1038/ng0794-353

[15] Welander, J., Larsson, C., Backdahl, M., Hareni, N., Sivler, T., Brauckhoff, M., Soderkvist, P. and Gimm, O. (2012) Integrative Genomics Reveals Frequent Somatic NF1 Mutations in Sporadic Pheochromocytomas. Human Molecular Genetics, 21, 5406-5416. http://dx.doi.org/10.1093/hmg/dds402 